\title{
CÃO QUE LADRA NÃO MORDE? A TUTELA COLETIVA CONSUMERISTA NA AMÉRICA LATINA ${ }^{1}{ }_{-2-3}$
}

\section{ALL BARK AND NO BITE? CONTEMPORARY CONSUMER REDRESS IN LATIN AMERICA}

Manuel A. Gómez

Graduação em Direito (UCAB), Especialização em Processo Civil (UCAB), Mestrado (Stanford), Doutorado (Stanford). Professor de Direito e Reitor Associado de Estudos Internacionais e de Graduação na Faculdade de Direito da Universidade Internacional da Flórida. Estados Unidos.E-mail: magomez@fiu.edu

RESUMO: Este artigo descreve a situação atual da proteção ao consumidor na América Latina, com atenção especial aos esforços recentes realizados, tanto em nível nacional, como regional, e aos desafios enfrentados. Ele examina o panorama da tutela coletiva consumerista na região e também discute o uso de litígios transnacionais como uma estratégia corretiva para as deficiências do regime de proteção ao consumidor latinoamericano. Como mostra o artigo, a despeito das muitas diferenças entre os sistemas jurídicos nacionais dos países latino-americanos, tem havido algumas tentativas de alcançar a sincronização regional. Desde o anteprojeto da CIDIP-VII elaborado sob a égide da Organização dos Estados Americanos ("OEA"), ao significativo esforço empreendido pela Conferência das Nações Unidas para o Comércio e o Desenvolvimento

\footnotetext{
${ }^{1}$ Artigo recebido em 12/09/2021, sob dispensa de revisão.

2 Trata-se de tradução do artigo "All Bark and no Bite? Contemporary Consumer Redress in Latin America", de autoria de Manuel A. Gómez, publicado, em sua versão original, em inglês, na Stellenbosch Law Review, ano de 2019, vol. 3, n. 3 e disponível em https://journals.co.za/doi/10.10520/EJC16801a6636. A tradução do texto para a publicação em português na Revista Eletrônica de Direito Processual foi feita por Larissa Clare Pochmann da Silva, Carla Teresa Bonfadini de Sá, Fabiana Marcello Gonçalves Mariotini, Alanna Martins e Maria Eduarda de Paiva Miguez.

${ }^{3} \mathrm{O}$ autor agradece ao Dr. Theo Broodryk e ao Dr. Stefaan Voet, pelo convite para participar da "International Conference on Consumer Redress", realizada na Faculdade de Direito da Universidade de Stellenbosch em abril de 2018, que inspirou este artigo. Também é grato aos participantes da conferência e outros colegas por suas valiosas percepções e comentários.
} 
(“UNCTAD”) com o apoio do governo suíço; vários países agora podem coordenar suas atividades e trabalhar para harmonizar seus regimes jurídicos. Não obstante essa perspectiva otimista, ainda existem alguns obstáculos importantes que se interpõem e que impediram esses sistemas modernizados de proteção ao consumidor de atingir alguns de seus objetivos. Ao concluir o artigo, sugeriu-se, como uma forma possível de mitigar os problemas existentes, que os países latino-americanos prestem mais atenção em assegurar que os consumidores tenham acesso a meios locais e eficazes de proteção judicial (em outras palavras, que os remédios existentes não apenas "ladrem, mas também mordam".

PALAVRAS-CHAVE: Proteção consumerista na América Latina; tutela coletiva; litígios transnacionais; sistemas legais dos países da América Latina; sincronização regional.

ABSTRACT: This article describes the current status of consumer protection in Latin America with particular attention to the recent efforts pursued both at the national and regional levels and the challenges faced. It surveys the landscape of consumer redress in the region and also discusses the use of transnational litigation as a remedial strategy for the shortcomings of the Latin American consumer protection regime. As the article shows, despite many differences among the national legal systems of Latin American countries, there have been some attempts to achieve regional synchronisation. From the CIDIP-VII draft produced under the aegis of the Organization of American States ("OAS"), to the significant effort undertaken by United Nations Conference of Trade and Development ("UNCTAD") with the support of the Swiss government; several countries are now able to coordinate their activities and work toward harmonising their legal regimes. Notwithstanding this optimistic outlook, there are still some important obstacles that stand in the way and that have prevented these modernised consumer protection systems from realising some of its goals. As the article concludes, one possible way to mitigate the existing problems would be if Latin American countries paid more attention to ensuring that consumers have access to local and effective means of judicial protection; in other words, that the existing remedies not only bark but also bite. 
Rio de Janeiro. Ano 16. Volume 23. Número 1. Janeiro a Abril de 2022

Periódico Quadrimestral da Pós-Graduação Stricto Sensu em Direito Processual da UERJ

Patrono: José Carlos Barbosa Moreira (in mem.). ISSN 1982-7636. pp. 945-973 www.redp.uerj.br

KEYWORDS: Consumer protection in Latin America; consumer redress; transnational litigation; legal systems of Latin American countries; regional synchronisation.

\section{INTRODUÇÃO: NO CAMINHO DA RECUPERAÇÃO ECONÔMICA E A NECESSIDADE DE TUTELA DE CONSUMIDORES E USUÁRIOS NA AMÉRICA LATINA}

As previsões econômicas e políticas gerais da América Latina são promissoras ${ }^{4}$. No final de 2018, o crescimento do produto interno bruto real ("PIB") da região atingiu $1,7 \%{ }^{5}$. A previsão é ainda mais promissora para 2019, quando o crescimento real do PIB deverá aumentar para pelo menos $2,6 \%{ }^{6}$. Com duas exceções - Venezuela e Nicarágua - a estabilidade política também predomina na região. A realização de eleições presidenciais de forma pacífica em vários países importantes, apesar da presença crescente do populismo e vários escândalos de corrupção, reforçou a ideia de que a região está comprometida com a democracia, o que aumentou a confiança dos atores econômicos ${ }^{7}$.

O consumo é um dos fatores que mais contribuem para a perspectiva econômica regional otimista ${ }^{8}$. Ao contrário do passado não tão distante, quando as relações de

\footnotetext{
${ }^{4}$ B Miller \& K Steiker-Ginzberg "Projected GDP Growth in Latin America for 2018" (undated) Americas Quarterly. Disponível em: https://www.americasquarterly.org/content/projected-gdp-growth-latinamerica-2018. Acesso:16/02/2019.

${ }^{5}$ Com exceção da Venezuela. Remete-se a: A Werner Latin America and the Caribbean in 2019: A Moderate Expansion (25-01-2019) IMFBlog <https://blogs.imf.org/2019/01/25/latin-america-and-thecaribbean-in-2019-a- moderate-expansion/> (acesso em 15-04-2019).

${ }^{6}$ Banco Mundial, "Global Economic Prospects: Latin America and the Caribbean Brief" (09-01-2018) Worldbank <https://www.worldbank.org/en/region/lac/brief/global-economic-prospects-latin-americaand-the-caribbeana> (acesso em 16-02-2019).

7 JM Ruiz "Latin America: The north-south divide" (27-02-2017) El Pais <https://elpais.com/ elpais/2017/02/27/inenglish/1488193792_043854.html> (acesso em 16-02-2019).

${ }^{8}$ Werner Latin America and the Caribbean in 2019: A Moderate Expansion (25-01-2019) IMFBlog.
} 
consumo eram predominantemente realizadas presencialmente, hoje as transações são cada vez mais feitas por meios eletrônicos ${ }^{9}$ e por plataformas omni-channel ${ }^{10}$.

A indústria de comércio eletrônico latino-americana vale 60 (sessenta) bilhões de dólares, o que equivale a 3\% de todas as vendas regionais formais no varejo - e "projetase que continue crescendo a taxas de dois dígitos (15\% a 20\%)"11. Neste novo ambiente de transações, é cada vez mais comum que consumidores, usuários e provedores estejam localizados em jurisdições diferentes, o que significa a aplicação de leis igualmente diversas.

Da mesma forma, muitos produtos são hoje projetados (e sujeitos às regulamentações de uma jurisdição), fabricados em outra, e distribuídos em um terceiro país, para serem finalmente vendidos. A consequência é que cada etapa da cadeia produtiva provavelmente estará sujeita a uma lei diferente, criando assim uma miscelânea regulatória.

$\mathrm{Na}$ maioria das vezes, a regulamentação díspare de produtos e serviços de consumo é prejudicial aos consumidores e usuários localizados nos Estados onde as leis de proteção ao consumidor são frágeis ou de difícil implementação. Os fabricantes tendem a estar melhor posicionados do que os Estados e consumidores porque têm a flexibilidade de escolher jurisdições consideradas "amigáveis" para seus negócios. Os fabricantes de produtos multinacionais também são estrategicamente capazes de dividir a cadeia de produção entre diferentes países, protegendo-se assim de responsabilidades e outros riscos. Alguns se tornaram tão poderosos que poderíamos compará-los a um Estado soberano em termos de poder e influência ${ }^{12}$.

\footnotetext{
${ }^{9} \mathrm{O}$ termo Comércio Eletrônico, e-commerce ou eCommerce "é um tipo de modelo de negócios ou segmento de um modelo de negócios maior, que permite a uma empresa ou indivíduo conduzir negócios em uma rede eletrônica, normalmente a internet". Investopedia "eCommerce" () <https://www.investopedia.com/ terms/e/ecommerce.asp> (acesso em 16-02-2019). Acesse, também, OECD "Protección del consumidor y comercio electrónico, Capítulo 13, in Políticas de banda ancha para América Latina y el Caribe: Un manual para la economía digital" (2016) <https://www.oecd-ilibrary.org/science-and-technology/ politicas-debanda-ancha-para-america-latina-y-el-caribe/proteccion-del-consumidor-y-comercioelectronico_9789264259027-16-es> (acesso em 16-02-2019).

${ }^{10} \mathrm{~S}$ Dennis "Omnichannel is Dead. Long Live Omnichannel” (23-03-2017) Forbes <https://www.forbes. $\mathrm{com} /$ sites/stevendennis/2017/03/23/omni-channel-is-dead-long-live-omni-channel/\#206ec7835215> (acesso em 16-02-2019).

11 M Cárdenas "LATAM Consumer \& Retail: The Good, the Bad and Ugly for 2018" (28-01-2018) Perspectiva, Market Insights for Success in Latin America <https://amiperspectiva.americasmi.com/latamconsumer-retail-the-good-bad-and-ugly-for-2018/> (acesso em 16-02-2019).

${ }^{12}$ M Gómez "More Risk, Better Regulation: A View from the World of Transnational Litigation" (2016) 8 European Journal of Risk Regulation (2016) 99.
} 
Em muitos países, o contrapeso para o comportamento potencialmente abusivo das empresas vem da regulamentação governamental. No entanto, as leis e os agentes politicos nem sempre são capazes de regulamentar o setor privado com eficiência devido à burocracia, aos obstáculos políticos e à pressão de grupos de interesse. O resultado é uma espécie de jogo regulatório entre empresas e governos, cenário no qual os usuários estão frequentemente no meio.

Se olharmos para uma região como a América Latina, há países como o Brasil, por exemplo, que fizeram grandes avanços na modernização de sua infraestrutura de proteção ao consumidor (ou seja, legislação, agências e mecanismos de fiscalização), a ponto de até servir como referência comparativa com outros países da região e em outros lugares no que diz respeito à modernização de sua infraestrutura jurídica.

No outro extremo porém, encontramos países onde a regulamentação dos direitos consumeristas ficou para trás, permitindo assim que muitas formas de comportamentos lesivos ao consumidor continuem ocorrendo. Como resultado, alguns governos da região têm buscado diferentes estratégias para fortalecer sua legislação interna e minimizar ou corrigir a disparidade regulatória que existe na defesa do consumidor.

Esses esforços foram impulsionados por algumas iniciativas regionais importantes, como o Projeto de Convenção Interamericana sobre o Direito Aplicável aos Contratos e Transações Internacionais de Consumo elaborado sob a égide da Organização dos Estados Americanos ("OEA") 13. Apesar desses e de outros esforços louváveis, os resultados são (infelizmente) mistos.

Este artigo descreve, inicialmente, a situação atual da proteção ao consumidor na América Latina, com foco nos esforços recentes realizados em nível nacional e regional e nos desafios enfrentados. Analisa-se o panorama da reparação do consumidor e também se discute acerca do uso de litígios transnacionais como uma estratégia corretiva para as deficiências do regime de proteção ao consumidor latino-americano.

\footnotetext{
${ }^{13}$ Os esforços da OEA seguiram o incentivo da Assembleia Geral das Nações Unidas dirigido aos governos, no contexto regional e sub-regional, para desenvolver políticas, mecanismos de intercâmbio de informações e outros compromissos compatíveis com as obrigações comerciais internacionais. Remete-se a: Assembleia Geral das Nações Unidas, Diretrizes sobre Proteção ao Consumidor UN Doc A / RES / 39/248 (16 de abril de 1985) <http://www.un.org/documents/ga/res/39/a39r248.htm> (acesso em 15-02-2019).
} 
O capítulo seguinte (capítulo 2) apresenta uma descrição das principais iniciativas contemporâneas voltadas à modernização e à harmonização das políticas de proteção ao consumidor na região da América Latina, promovidas por agências multilaterais e estrangeiras de desenvolvimento.

O capítulo 3 descreve o arcabouço constitucional e legal que elevou a proteção ao consumidor na região. O capítulo 4, por sua vez, tem como foco o direito latino-americano e retrata como, apesar da existência de uma infraestrutura jurídica adequada para indenização ao consumidor em diferentes países da região, os consumidores latinoamericanos ainda optam por ajuizar ações nos Tribunais dos Estados Unidos. Além disso, o capítulo 4 explica como, apesar das vantagens da litigância civil nos Tribunais americanos, ainda existem alguns obstáculos que impedem os demandantes estrangeiros. O capítulo 4 é encerrado com uma análise acerca do uso de mecanismos constitucionais de proteção dos consumidores na América Latina.

Ao final do artigo, há uma breve conclusão.

\section{AS DIFICULDADES DE HARMONIZAÇÃO E COOPERAÇÃO REGIONAL EM MATÉRIA DE PROTEÇÃO AO CONSUMIDOR NA AMÉRICA LATINA}

A harmonização das leis e políticas de proteção ao consumidor entre os países latino-americanos é difícil, em parte porque seus sistemas jurídicos nacionais são diferentes. Uma suposição comum, mas equivocada, é a de que a América Latina compreende um grupo uniforme de nações irmãs. Mas, um olhar mais atento às suas realidades sociais, econômicas e políticas mostra o contrário. As diferenças entre os sistemas Jurídicos latino-americanos fazem com que o termo "Direito Latino-americano", frequentemente utilizado, seja, na melhor das hipóteses, confuso ${ }^{14}$.

A ideia enganosa de um sistema jurídico regional unitário ou mesmo harmonizado deriva do fato de que a maioria dos países latino-americanos compartilham raízes históricas comuns, por se tartar de ex-colônias dos impérios espanhol e português. Isso obviamente teve um efeito no desenvolvimento de suas leis e instituições jurídicas. Mas, a independência da Espanha e de Portugal ocorreu há dois séculos e a maioria dos países

\footnotetext{
${ }^{14}$ JL Esquirol "Continuing Fictions of Latin American Law” (2003) 55 Fla L Rev 41.
} 
latino-americanos seguiram seus próprios caminhos, às vezes em direções muito diferentes daquelas seguidas por seus vizinhos. A submissão aos mesmos regimes jurídicos impostos pelas potências coloniais durante a fase de pré-independência não necessariamente impactou na uniformização dos sistemas jurídicos nacionais pósindependência.

Sensíveis às possíveis vantagens da integração regional e sub-regional, as últimas seis décadas testemunharam diversos esforços de integração realizados na região relacionados com o comércio e outros assuntos ${ }^{15}$. Os exemplos mais importantes são o Mercado Comum do Sul ("MERCOSUL"), a Comunidade Andina de Nações ("CAN"), a Comunidade do Caribe ("CARICOM"), a Associação de Livre Comércio do Caribe (“CARIFTA"), o Acordo de Livre Comércio entre a República Dominicana e a América Central ("DR-CAFTA"), a Aliança Bolivariana para os Povos da Nossa América (“ALBA") e a União de Nações Sul-Americanas ("UNASUL”).

Infelizmente, as mais promissoras tentativas de integração ficaram aquém de seus objetivos originais - e seu destino ficou sujeito ao pêndulo político da região. Outros arranjos regionais resultaram em um fracasso total, como recentemente demonstrado pela desintegração da $\operatorname{ALBA}^{16}$ e da UNASUL ${ }^{17}$.

De forma instigante, os promotores dos diferentes esforços de integração latinoamericana nunca viram a proteção do consumidor como uma prioridade, apesar de sua óbvia importância para a sociedade e sua estreita conexão com o avanço do comércio internacional e desenvolvimento econômico. Existem, no entanto, algumas exceções, como é o caso da iniciativa lançada há mais de uma década por vários membros da OEA de "participar dos trabalhos preparatórios para a redação de instrumentos interamericanos relacionados"18 à proteção do consumidor ${ }^{19}$.

\footnotetext{
${ }^{15}$ M Gómez "The South American Way: Sub-regional integration under ALBA and UNASUL and international dispute resolution" (2017) 58 Húngaro Journal of Legal Studies-Acta Juridica Hungarica 449. ${ }^{16}$ Para suas iniciais em espanhol: Alianza Bolivariana para los pueblos de nuestra América. Remete-se a: $<$ tp://www. portalalba.org/> (acesso em 16-02-2019).

${ }^{17}$ Para suas iniciais em espanhol, Unión de Naciones Suramericanas. Veja, União das Nações SulAmericanas <https:// www.unasursg.org/en> (acesso em 16-02-2019).

${ }^{18}$ Organização dos Estados Americanos <http://www.oas.org/dil/cidip-vii_home.htm> (acesso em 16-022019).

${ }^{19}$ Resolução da Assembleia Geral da Assembleia Geral da Organização dos Estados Americanos AG/RES. 2065 (XXXV-O/05), Sessão Plenária de 7 de Junho de 2005.
} 
Um dos primeiros passos para uma harmonização regional das políticas de proteção ao consumidor foi a proposta apresentada pelo governo do Brasil (e posteriormente aderida por Argentina e Paraguai), a qual consiste em um projeto de “Convenção sobre Proteção ao Consumidor e Escolha de Lei, um Projeto de Lei Modelo sobre Jurisdição e Conflito de Leis, e também um esboço para um projeto de Lei Modelo sobre Mecanismos de Reparação ao Consumidor"20.

Três protocolos opcionais complementaram esses projetos com o objetivo de facilitar a implementação da convenção por potenciais signatários. O objetivo geral dessas iniciativas era o de incentivar os Estados Membros da OEA a "fornecer proteção legal aos consumidores em seu relacionamento com os fornecedores, para fornecer benefícios econômicos aos consumidores, aumentando a disponibilidade e diminuindo os custos dos produtos, e para fornecer confiança ao consumidor no mercado"21.

Apesar da extensão regional das propostas, apenas dois governos (Canadá22 e Estados Unidos ${ }^{23}$ ) apresentaram comentários formais ${ }^{24}$. As observações do Canadá foram centradas no escopo do projeto de Lei Modelo, sobre a necessidade de esclarecimentos acerca da definição dos consumidores, problemas relativos ao conflito de leis e outras questões relacionadas ${ }^{25}$. Além disso, o Canadá introduziu um projeto de Lei Modelo sobre jurisdição e conflito de leis ${ }^{26}$. Apesar de algumas semelhanças com a proposta brasileira

\footnotetext{
${ }^{20}$ Proposta Conjunta dos Governos do Brasil, Argentina e Paraguai ("Proposta de Buenos Aires") à Sétima Conferência Interamericana Especializada de Direito Internacional Privado (CIDIP-VII), documento CP/CAJP-2652/08 acrescentam 4 corr. 1, 19 de março de $2010<$ http://www.oas.org/dil/CIDIPVII_consumer_protection. htm> (acesso em 04-02-2019).

${ }^{21}$ Introdução Explicativa ao Encontro de Especialistas realizado pela OEA — Porto Alegre, Brasil, 2 a 4 de dezembro de 20061 <https://www.oas.org/dil/experts_meeting_porto_alegre_2-4_2006.pdf> (acesso em 04-02-2019).

${ }^{22}$ Lista de comentários do Canadá à proposta conjunta da Argentina, Brasil e Paraguai para um projeto de Convenção Interamericana sobre a Lei Aplicável a Alguns Contratos e Transações Internacionais de Consumo, documento da OEA/Ser/G CP/CAJP-2823/10 de 14 de abril de 2010.

${ }^{23}$ Proposta dos Estados Unidos da América para a Sétima Conferência Interamericana Especializada em Direito Internacional Privado (CIDIP-VII), documento CP/CAJP-2837/10 de 21 de abril de 2010.

${ }^{24}$ É importante ressaltar que "especialistas de apenas onze países participaram da reunião" organizada pelo Brasil em 2006, onde foram discutidas as diversas propostas do CIDIP-VII. Além disso, ao contrário do que normalmente ocorre nesses tipos de iniciativas, "nenhum grupo de trabalho foi criado pela OEA para buscar harmonizar as propostas". Veja, AF Pérez "Defesa do Consumidor nas Américas: Uma Segunda Onda de Revoluções Americanas?" (2008) 5 U St. Thomas LJ 698, 702.

${ }^{25}$ Lista de comentários do Canadá à proposta conjunta da Argentina, Brasil e Paraguai para um projeto de Convenção Interamericana sobre a Lei Aplicável a Alguns Contratos e Transações Internacionais de Consumo, documento da OEA/Ser/G CP/CAJP-2823/10 de 14 de abril de 2010.

${ }^{26}$ Pérez (2008) U St. Thomas LJ 703.
} 
de um tratado sobre a adoção da "lei do domicílio do consumidor como lei padrão"27 e a imposição de "limites à autonomia na lei aplicável e no local do litígio"28, a proposta canadense optou por adotar um critério subjetivo para determinar a escolha da lei ou escolha do Tribunal. Como resultado, o consumidor seria capaz de "anular uma cláusula de eleição de foro ou de lei aplicável em um contrato e processar em seu foro a lei local, " a menos que o fornecedor demonstre que adotou medidas razoáveis para evitar a celebração de contratos de consumo com consumidores residentes naquele Estado"29.

Os Estados Unidos submeteram extensos comentários à proposta das três nações sul-americanas, e também ao documento canadense. Uma das principais preocupações dos Estados Unidos era o escopo limitado das propostas, seu efeito potencialmente adverso aos consumidores e à economia, e sua falha em contribuir efetivamente para uma harmonização regional ${ }^{30}$. Em relação a este último, os Estados Unidos apontaram a falta de uniformidade que existia em toda a região no que diz respeito à legislação aplicável e aos princípios de jurisdição competentes e à inadequação de algumas soluções tentadas, particularmente no domínio das transações eletrônicas de consumo ${ }^{31}$. Os Estados Unidos também consideraram que as propostas supracitadas entraram em conflito com outras decisões adotadas pelos membros da OEA em relação à escolha do direito, como a Convenção Interamericana sobre o Direito Aplicável aos Contratos Internacionais $\left(\right.$ "CIDIP-V") ${ }^{32}$.

Uma área de maior preocupação para os Estados Unidos foi a rápida expansão e a crescente importância das transações comerciais eletrônicas e transfronteiriças, que por sua vez exigiram a criação de uma regulamentação adequada quadro tanto a nível nacional quanto regional. "A ausência de um arcabouço instituído na prática para a proteção dos consumidores nas Américas", disseram os Estados Unidos, "poderia limitar o crescimento futuro do comércio eletrônico transfronteiriço $B 2 C^{\prime \prime 3}$.

\footnotetext{
27703

${ }^{28} 703$

${ }^{29} 703$

${ }^{30}$ Proposta dos Estados Unidos da América para a Sétima Conferência Interamericana Especializada em Direito Internacional Privado (CIDIP-VII), documento CP/CAJP-2837/10 de 21 de abril de 2010.

${ }^{31}$ Remete-se à nota 5.

${ }^{32} \mathrm{Idem}$

${ }^{33}$ Remete-se à nota 11.
} 
Como resultado de suas observações, os Estados Unidos propuseram orientações legislativas e Códigos Modelo de Solução de Conflito e Tutela Ressarcitória, que, segundo acreditavam, abordariam as áreas mais críticas de preocupação em relação à defesa do consumidor na região. A proposta dos Estados Unidos foi particularmente abrangente, pois continha um esboço com orientações sobre mecanismos de reparação do consumidor e quatro leis de modelo adicionais relativas à regulamentação de "mecanismos eficazes de reparação do consumidor por meio de resolução alternativa de litígios, particularmente para lesões com pequeno valor monetário"34.

Apesar de contribuir para revigorar o debate político na região e conscientizar sobre a importância de um tratamento harmonizado da defesa do consumidor, alguns especialistas opinaram no sentido de que "nenhuma das propostas atuais, tomadas individual ou em conjunto, poderia solucionar os problemas para a efetiva defesa do consumidor no Hemisfério Ocidental" ${ }^{\prime 3}$. Os principais impedimentos para a solução regional não resultam apenas da "dificuldade de encaixar este novo tema na história e nas práticas institucionais específicas do processo da CIDIP, mas também devido à complexidade técnica e intratabilidade do problema" ${ }^{\prime 36}$.

Por intermédio de uma iniciativa não relacionada às discussões da OEA, a Conferência das Nações Unidas sobre Comércio e Desenvolvimento ("UNCTAD") solicitou uma série de estudos voltados a avaliar as necessidades e prioridades de vários países latino-americanos em relação à concorrência e à defesa do consumidor ${ }^{37}$. As Diretrizes das Nações Unidas para a Defesa do Consumidor de $1999^{38}$ foram a base dos

\footnotetext{
${ }^{34}$ Organização dos Estados Americanos "CIDIP VII Consumer Protection nos Estados Unidos" (sem data) OEA. Disponível: http://www.oas.org/dil/CIDIP-VII_consumer_protection_united_states.htm. Acesso: 05/02/2019). Veja também, Proposta dos Estados Unidos da América para a Sétima Conferência Interamericana Especializada em Direito Internacional Privado (CIDIP-VII), documento CP/CAJP2652/08 acrescentar 1 rev. 1, 3 de maio de 2010 e o Projeto [Lei modelo/Quadro Cooperativo] para Resolução Eletrônica de Disputas de Consumidores de Comércio Eletrônico Transfronteiriços de 22 de fevereiro de 2010; Projeto de Lei do Modelo: Resolução de disputas alternadas para sinistros de cartão de pagamento do consumidor de 18 de fevereiro de 2010; Projeto de Lei modelo sobre Pequenas Reivindicações de 12 de fevereiro de 2010; Projeto de Lei Modelo de Reparação Governamental para consumidores, incluindo além das fronteiras, em 12 de fevereiro de 2010.

${ }^{35}$ Pérez (2008) U St. Thomas LJ 698, 699.

36700.

${ }^{37}$ Remete-se a P Brusick, AM Alvarez \& PM Horna Fortalecendo instituições e capacidades na área de Política de Concorrência e Defesa do Consumidor,documento dasNações Unidas UNCTAD/DITC/CLP/2004/3 (2004).

${ }^{38}$ Conferência das Nações Unidas sobre Comércio e Desenvolvimento, Diretrizes das Nações Unidas sobre Defesa do Consumidor ("UNGCP"), Resolução do Conselho Econômico e Social 1999/7 de 26 de Julho
} 
estudos. O projeto inicial envolveu diversas missões (na Bolívia, em Costa Rica, El Salvador, Honduras, Nicarágua, Guatemala e no Peru), bem como inúmeras reuniões com funcionários do governo, politicos e especialistas internacionais ${ }^{39}$. Surpreendentemente, o apoio financeiro mais significativo que tornou esses esforços em realidade veio de duas agências suíças: a Secretaria de Assuntos Econômicos ("SECO") e a Comissão de Concorrência ("COMCO") ${ }^{40}$.

O resultado da primeira missão apelidada de "Fase 1" foi um relatório de 185 (cento e oitenta e cinco) páginas com recomendações específicas para cada um dos países participantes $^{41}$. Durante a primeira fase, a UNCTAD buscou avaliar as necessidades e identificar as prioridades de cada país participante em relação às políticas de consumo e concorrência $^{42}$. Várias atividades, incluindo duas oficinas sub-regionais, foram realizadas como forma de promover um intercâmbio entre formuladores de políticas e especialistas. O relatório final concentrou-se em vários aspectos importantes e incluiu recomendações que focavam na(o): (a) modernização e o fortalecimento da legislação de defesa do consumidor e (b) fortalecimento e a capacitação de órgãos governamentais especialmente dedicados, redes de defesa do consumidor e mecanismos de cooperação que envolvem atores da sociedade civil.

O relatório também vislumbrou um espectro mais amplo de cooperação nos níveis bilateral, sub-regional e regional, envolvendo tanto agências governamentais quanto atores da sociedade civil. Os países beneficiários foram divididos em dois subgrupos de acordo com sua proximidade geográfica. Bolívia e Peru formaram o primeiro subgrudo e Costa Rica, El Salvador, Honduras, Nicarágua e Guatemala formaram o outro subgrupo ${ }^{43}$.

Em 2004, o SECO tornou-se o principal patrocinador do projeto UNCTAD, que evoluiu para um programa de assistência técnica - de longo prazo apelidado de Políticas de Concorrência e Defesa do Consumidor para a América Latina ("COMPAL"). Seu objetivo era "fornecer aos países em desenvolvimento ferramentas para se beneficiar das

de 1999. As Diretrizes foram revisadas e aprovadas pela Assembleia Geral na Resolução 70/186 de 22 de dezembro de 2015. Documento da ONU UNCTAD/DITC/CPLP/MISC/2016/1 <http://unctad.org/en/PublicationsLibrary/ ditccplpmisc2016d1_en.pdf> (acessado 15-02-2019).

${ }^{39}$ Remete-se à nota $n^{\circ} 3$.

${ }^{40}$ Remete-se à nota $n^{\circ} 7$.

${ }^{41}$ Idem.

${ }^{42}$ Idem.

${ }^{43}$ Idem. 
políticas de concorrência em seus mercados e alcançar o bem-estar do consumidor por meio de preços mais baixos, melhor qualidade e uma variedade mais ampla de escolha para os consumidores ${ }^{\prime \prime 4}$.

O COMPAL também procurou "facilitar a adoção e implementação de leis de concorrência nos países beneficiários que haviam empreendido esforços para elaborar suas leis ${ }^{\prime \prime 5}$, como Nicarágua, El Salvador e Bolívia. Outro objetivo do COMPAL era fornecer um apoio mais robusto à aplicação da legislação antitruste na Costa Rica e no Peru, os dois países mais bem equipados do grupo ${ }^{46}$. Uma segunda fase ("COMPAL II") funcionou de 2009 a 2012 e incluiu a Colômbia. Durante esse período, "mais onze países aderiram, autofinanciamento sua participação" ${ }^{\prime 47}$.

Nos últimos anos, o COMPAL continuou a expandir-se para outros países e, atualmente, abrange 75\% (setenta e cinco por cento) da América Latina. Seus 17 (dezessete) membros incluem as maiores economias da região: Argentina, Brasil e México. No início de 2018, a Comunidade Andina ganhou o status de observadora do COMPAL, facilitando, assim, a implementação das políticas do COMPAL entre os países andinos, a saber: Bolívia, Colômbia, Equador e Peru. A terceira fase do programa ("COMPAL III") foi lançada em 2015 e está centrada na "consolidação das capacidades adquiridas e no aprofundamento da cooperação regional" ${ }^{48}$. Além disso, o COMPAL III pretende fornecer ao "setor privado ferramentas para garantir o cumprimento voluntário e capacitar os consumidores globais no século XXI"49.

Todos os anos, os membros do COMPAL participam de uma série de atividades que incluem grupos de trabalho, conferências e outras reuniões ${ }^{50}$. Também preenchem um questionário que fornece informações valiosas e ajuda a avaliar a implementação de

\footnotetext{
${ }^{44}$ Remete-se à nota $\mathrm{n}^{\circ} 9$.

${ }^{45}$ P Brusick, AM Alvarez \& PM Horna Fortalecimiento de instituciones y capacidades en el area de Políticas de Competencia y Protección and Consumidor UN document UNCTAD/DITC/CLP/2004/3 (2004) 11.

${ }^{46}$ Remete-se à nota $\mathrm{n}^{\circ} 9$.

${ }^{47}$ Remete-se a Compal "About Compal" (sem data) UNCTADCOMPAL Disponível em: https://unctadcompal.org/acerca-del- compal/. Acesso: 15/02/2019.

${ }^{48}$ Compal "About Compal" (sem data) UNCTADCOMPAL.

${ }^{49}$ Idem.

${ }^{50}$ COMPAL III Relatório Anual 2015-2016 4 <https://unctadcompal.org/documento/informe-annualcompal-iii-2015-2016/> (acessado 15-02-2019). Veja também, COMPAL III Relatório Anual 2016-2017 8. Disponível: https://unctadcompal.org/wp-content/uploads/2017/03/COMPAL-III_Informe-Anual-20162017.pdf. Acesso em 15-02-2019.
} 
suas estratégias coletivas. De acordo com o Relatório 2017-2018 ${ }^{51}$, todos os órgãos de defesa do consumidor da América Latina de língua espanhola (com exceção do México) são membros do COMPAL, tornando-se, portanto, a principal plataforma de cooperação regional nessa área ${ }^{52}$.

Uma organização particularmente importante que recentemente ingressou no COMPAL é o Conselho Administrativo de Defesa Econômica (CADE) ${ }^{53}$. O COMPAL também se tornou cada vez mais autossustentável, a ponto de seus membros financiarem a maioria de suas atividades e apenas $30 \%$ (trinta por cento) são financiados pela $\mathrm{SECO}^{54}$. Apesar desta previsão financeira positiva, os membros do COMPAL continuaram a buscar apoio externo e desenvolveram comunicações com representantes de pelo menos sete países europeus, mais Estados Unidos e Canadá. Se obtido, esse financiamento externo substituiria o financiamento do SECO para fins de cobertura das necessidades orçamentárias da organização ${ }^{55}$.

As atividades mais recentes do COMPAL se concentraram em duas estratégias distintas de intervenção: a consolidação das capacidades adquiridas e o aprofundamento da cooperação regional ${ }^{56}$, bem como a conformidade voluntária do setor privado com as leis e políticas de concorrência e consumo ${ }^{57}$. Em relação ao primeiro, pelo menos 10 (dez) agências latino-americanas de defesa do consumidor firmaram acordos de cooperação ou intercâmbio. A segunda estratégia de intervenção foi centrada nas atividades realizadas na Colômbia e Peru ${ }^{58}$. Esses esforços ocorreram em conjunto com uma série de reformas legislativas voltadas para modernizar o quadro de defesa do consumidor nos diferentes países da região.

\section{CONJUNTURA CONSTITUCIONAL E LEgAL DA PROTEÇÃo AO CONSUMIDOR NA AMÉRICA LATINA}

\footnotetext{
51 COMPAL III Relatório Anual (2017-2018). Disponível: https://unctadcompal.org/wpcontent/uploads/2018/07/ COMPAL-III_Informe-Annual-2017-2018.pdf. Acesso em 15/02/2019.

${ }^{52}$ Remete-se à nota $\mathrm{n}^{\circ} 7$.

${ }^{53}$ UNCTAD "O Brasil entra no Programa COMPAL da UNCTAD" (07-02-2018) UNCTAD Disponível em: http://unctad.org/ en/pages/newsdetails.aspx? OriginalVersionID=1667. Acesso: 15/02/2019.

${ }^{54}$ UNCTAD "O Brasil integra o Programa COMPAL da UNCTAD" (07-02-2018) UNCTAD 5.

55 UNCTAD "O Brasil integra o Programa COMPAL da UNCTAD" (07-02-2018) UNCTAD 6.

${ }^{56}$ UNCTAD "O Brasil adere ao Programa COMPAL da UNCTAD" (07-02-2018) UNCTAD 9-36.

${ }^{57}$ UNCTAD "O Brasil adere ao Programa COMPAL da UNCTAD" (07-02-2018) UNCTAD 37-40.

${ }^{58}$ UNCTAD "O Brasil integra o Programa COMPAL da UNCTAD" (07-02-2018) UNCTAD 38.
} 
Diversos países da América Latina elevaram a proteção ao consumidor (ou, mais amplamente, a proteção dos direitos individuais e coletivos) ao mais alto nível, incluindo disposições específicas em Constituições, que reconhecem sua importância ${ }^{59}$ e que impõem aos órgãos do Estado o dever de promover e proteger tais direitos ${ }^{60}$. Algumas disposições, como as incluídas nas Constituições da Argentina, ${ }^{61}$ Brasill $^{62}$ e Peru, ${ }^{63}$ mencionam explicitamente consumidores e usuários; enquanto em outras constituições México $^{64}$ e Equador ${ }^{65}$, por exemplo - a referência é à proteção dos direitos individuais e coletivos em geral, ficando a aplicação aos consumidores e usuários implícita.

Com algumas exceções, as disposições constitucionais que se referem à proteção do consumidor "são frequentemente enquadradas como diretrizes gerais (normas programáticas), que exigem demais ações legislativas para desenvolver os meios pelos quais indivíduos e grupos socialmente identificáveis podem obter compensação por danos"66.

O segundo nível de proteção ocorre por meio de leis especiais que definem e regulamentam os direitos substanciais dos consumidores e usuários. Praticamente todos

\footnotetext{
${ }^{59}$ AMR Sánchez; LFG Salazar "Esfuerzos Latinoamericanos en torno a los derechos del consumidor: CAN y Mercosur" (2016) 89.1 Revista Relaciones Internacionales 171.

${ }^{60}$ Veja, eg, (1) Argentina, Constitución Nacional [Const. Nac.] 22 ago. 1994, art. 42 (Arg.); (2) Brasil, Constituição Federal [C.F.] 5 out. 1988, art. 5 (Brasil); (3) Colômbia, Constitución Política de Colombia [C.P.] 4 jul. 1991, art. 78; (4) Costa Rica, Constitutión Política De La Republica De Costa Rica [Const.] 7 nov. 1949, art. 46; (5) Equador, Constitución Política de la República del Ecuador [Const.] 28 set. 2008, art. 92; (6) El Salvador, Constitución de la República de El Salvador [Const.] 20 dez. 1983, art. 101; (7) Guatemala, Constitución Política de la República de Guatemala [Const.] 31 mai. 1985, arts. 119 e 130; (8) Honduras, Constitución Política de la República de Honduras [Const.] 4 mai. 2005, arts. 331 e 347; (9) Nicarágua, Constitución Politíca de la República de Nicaragua [Cn.] 9 jan. 1987, art. 105, La Gaceta, Diário Oficial [L.G.]; (10) Panamá, Constitución Politíca de la República de Panama [Const.] 11 out. 1972, art. 279; (11) Paraguai, República de Paraguay, Constitución Política de 1992 [Const.] 20 jun. 1992, art. 72; (12) Peru, Constitución Política del Perú 1993 [Const.] 31 dez. 1993, art. 65; e (13) Venezuela, Constitución de la República Bolivariana de Venezuela [Const.] 15 dez. 1999, art. 117.

${ }^{61}$ Constitución de la Nación Argentina, Lei n. ${ }^{\circ} 24.430$ de 15 de dezembro de 1994, art. 42.

${ }^{62}$ Constituição da República Federativa do Brasil de 1988, art. 170.

${ }^{63}$ Constitución Política del Peru 1993, art. 65.

${ }^{64}$ Constitución Política de los Estados Unidos Mexicanos, que reforma a de 5 de fevereiro de 1857, 5 de fevereiro de 1917, arts. 128 e 131.

${ }^{65}$ Constitución de la República del Ecuador, Registro Oficial 449 de 20 de outubro de 2008, arts. 215 e 216.

${ }^{66}$ M Gómez "Will the Birds Stay South? The Rise of Class Actions and Other Forms of Group Litigation Across Latin America" (2012) 43 Univ Miami Inter-American L Rev 3. Trecho original: "are often framed as general guidelines (normas programáticas, in Spanish) that call for further legislative action to develop the means through which individuals and socially identifiable groups are ableto obtain compensation for harms".
} 
Revista Eletrônica de Direito Processual - REDP.

Rio de Janeiro. Ano 16. Volume 23. Número 1. Janeiro a Abril de 2022

Periódico Quadrimestral da Pós-Graduação Stricto Sensu em Direito Processual da UERJ

Patrono: José Carlos Barbosa Moreira (in mem.). ISSN 1982-7636. pp. 945-973

www.redp.uerj.br

os países da região possuem uma lei de proteção ao consumidor em vigor. No entanto, a regulamentação das relações de consumo decorrentes do comércio eletrônico, computação em nuvem e outras novas tecnologias é geralmente escassa. Como resultado, a gestão destes novos desafios foi deixada para os Tribunais, que, por sua vez, desempenharam um papel fundamental no desenvolvimento de jurisprudência relevante que redefine o escopo da proteção ao consumidor em nível nacional. Previsivelmente, os Tribunais das maiores economias, como o do Brasil, têm sido os mais ativos nessa questão ${ }^{67}$.

Uma característica comum entre as várias leis nacionais de proteção ao consumidor é a inclusão de disposições relativas ao "estabelecimento de agências administrativas, ouvidorias e grupos de defesa investidos em funções que vão desde a formulação de políticas até a educação, treinamento e defesa em favor dos consumidores por meio de processos administrativos e judiciais" "68. Para esta finalidade, diversos países, incluindo Argentina ${ }^{69}$, Brasil $^{70}$, Chile $^{71}$, Colômbia ${ }^{72}$ e México, ${ }^{73}$ adotaram

\footnotetext{
${ }^{67}$ Veja: C Castro; C Reed; R de Queiroz "On the applicability of the Consumer Protection Code to cloud computing transactions in Brazil" (2013) 10 Script-Ed 459, 471: "Diferentes decisões judiciais têm discutido esse assunto no Brasil. O recente caso do Tribunal de Justiça de São Paulo da Google Brasil Internet Ltda. Vs. Adriano Schincariol, destacou justamente a aplicabilidade do direito do consumidor a essa relação... Outra decisão dispôs sobre a aplicabilidade do Código em situações online. Em 2011, um processo de litígio civil foi movido contra o Orkut em relação à proteção de imagem". Trecho original: "Different court decisions have discussed this matter in Brazil. The recent High Court of São Paulo case of Google Brasil Internet Ltda. V. Mr. Adriano Schincariol, highlighted precisely the applicability of consumer law to this relationship... A further decision ruled on the applicability of the Code to online situations. In 2011 a tort case was brought against Orkut in relation to image protection".

${ }^{68}$ Gómez (2012) Univ Miami Inter-American L Rev 3. Trecho original: "the establishment of administrative agencies, ombudsmen and defense groups vested with duties that range from policymaking to education, training, and advocacy on behalf of consumers through administrative and judicial processes".

${ }^{69}$ Ley de Defensa del Consumidor, Lei n. ${ }^{\circ}$ 26.361, de 12 de março de 2008, B.O. 31378, art. 25 (Argentina). Veja também: Halabi, Corte Suprema de Justicia de la Nacion [CSJN] [Corte Suprema de Justiça da Nação] 24 fev. 2009, "Halabi, Ernesto C. Poder Ejecutivo Nacional (P.E.N.) - Ley 25.873," dto. 1563/04 s/ amparo Lei n. ${ }^{\circ} 16.986$ (Argentina).

${ }^{70}$ Lei da ação civil pública, Lei n. ${ }^{0}$ 7.347, de 24 de julho de 1985 (Brasil). Disponível em: http://www.planalto.gov.br/ ccivil_03/Leis/L7347orig.htm. Acesso: 16/02/2019. Veja também: Código de Defesa do Consumidor de 1990, Lei n. ${ }^{\circ}$ 8.078, de 11 de setembro de 1990 (Brasil). Disponível em: http://www.planalto.gov.br/ccivil_03/leis/L8078.htm. Acesso: 16/02/2019.

${ }^{71}$ Ley de Protección al Consumidor, Lei n. ${ }^{\circ} 19.955,2$ jul. 2004, Diário Oficial [D.O.] (Chile).

72 Popular and Group Actions Act, L. 472, 5 ago. 1998, art. 1. Diário Oficial [D.O.] (Colômbia).

${ }^{73}$ Constitución Política de los Estados Unidos Mexicanos [C.P.] [Const.], reformada, título Primero, Capítulo I, De los Derechos Humanos y Sus Garantías, art. 17, Diario Oficial de la Federación [DO], 10 de junho de 2010 (México) (Denominação reformada por decreto publicado no DO em 10 de junho de 2010) adição do parágrafo terceiro foi publicada no DO em 29 de julho de 2010. Veja também: Decreto pelo qual se reforma e adiciona ao: Código Federal de Procedimientos Civiles, Código Civil Federal, Ley Federal de Competencia Económica, Ley Federal de Protección al Consumidor, Ley Orgánica del Poder Judicial de la Federación, Ley General del Equilibrio Ecológico y la Protección del Ambiente, Ley de
} 
mecanismos de tutela coletiva similares às ações coletivas comumente utilizadas nos Estados Unidos ${ }^{74}$, permitindo, assim, que grandes grupos de consumidores e usuários obtenham tutela de forma mais eficiente ${ }^{75}$.

No entanto, a regulamentação destes noveis veículos processuais ficou aquém de regular certos aspectos importantes, como requisitos de certificação de classe, questões permanentes sobre o grupo ou o representante de classe, disposições opt-in e opt-out, a possibilidade de permitir arranjos de taxas alternativas, financiamento externo de litígios e a inclusão de danos punitivos, exemplares ou de outros impedimentos ${ }^{76}$.

No tópico de veículos processuais, o cenário latino-americano de proteção ao consumidor, também vivenciou a crescente popularidade da arbitragem como mecanismo preferencial para resolver disputas entre consumidores e vendedores ${ }^{77}$. A despeito de ser percebida como meio problemático e inadequado para resolução de disputas de consumo, a arbitragem tem ganhado apoio na América Latina, em grande parte por sua suposta eficiência e acessibilidade ${ }^{78}$. A possibilidade de arbitragem nas disputas de consumo é expressamente permitida em algumas jurisdições - geralmente sob certas condições -, enquanto excluída em outras ${ }^{79}$.

Em alguns países, como o Brasil, a situação está longe de ser clara ${ }^{80}$. Neste país, a Lei de Arbitragem de 2015 “contém uma disposição geral que permite a arbitragem

Protección y Defensa al Usuario de Servicios Financieros, Diario Oficial de la Federación [DO], 30 de agosto de $2011 \quad$ (México). Disponível em: http://dof.gob.mx/nota_detalle.php?codigo=5206904\&fecha=30/08/2011. Acesso: 16/02/2019.

${ }^{74}$ Gómez (2012) Univ Miami Inter-American L Rev 3.

${ }^{75}$ Não obstante, a promulgação de legislação a respeito de ações coletivas não é por si só uma solução, e sua eficácia depende de uma variedade de fatores, incluindo a "política de regime". Para uma análise aprofundada sobre este fenômeno no contexto chileno, veja, Agustín Barroilhet "The Regime Politics Origins of Class Action Regulation" (2018) 19 Theoretical Inquiries L 363.

7649 Veja também, M Gómez "Like Migratory Birds - Latin American Claimants in U.S. Courts and the Ford- Firestone Rollover Litigation” (2005) 21 Southwest Journal of Law and Trade in the Americas 11.

77 Proconsumer, Sistema de Consumo Nacional de Arbitraje. Disponível em: http://www.proconsumer.org.ar/index. php/80-proconsumer/123-snac. Acesso: 16/02/2019.

78 Veja eg, J Espinoza Lozada; CM Lopez; V Vergaray Béjar “Arbitraje de Consumo, Escuela Nacional Indecopi” (2016) Indecopi 177-198. Disponível em: https://www.indecopi.gob.pe/documents/51084/126949/ ArbitrajeDeConsumo_2016/a70602fb-ac42b932-5ced-0430545ee966. Acesso: 16/02/2019.

${ }^{79}$ Veja, de forma geral, T Cole; P Ortolani; P Karacan; S Trindade Cardoso "Arbitration in the Americas: Report on a Survey of Arbitration Practitioners " University of Leicester \& Gentium Law (2018). Os dados subjacentes nos quais este relatório se baseou foram obtidos como parte de um projeto de pesquisa em que o autor colaborou com Tony Cole, Pietro Ortolani, Daniel de Andrade Levy, Paolo Vargiu e Masood Ahmed; com o apoio da Corte Internacional de Arbitragem e da Organização dos Estados Americanos.

${ }^{80}$ Há diversos casos decididos por tribunais brasileiros que trataram da arbitrabilidade de disputas contratuais entre empresas e consumidores ("B2C"). Veja, D Alcici Salomão "Effective methods of 


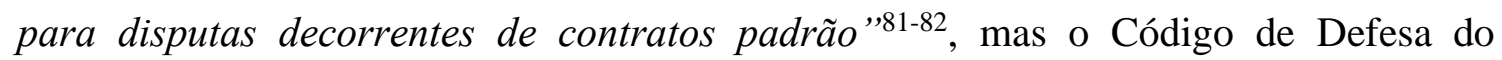
Consumidor "considera nula e sem efeito qualquer cláusula que obrigue a arbitragem em contrato $B 2 C^{\text {" } 83-84}$ No início de 2015, um projeto de lei do Senado continha texto que teria esclarecido a situação, mas um veto presidencial impediu que fosse aprovado como $1 \mathrm{ei}^{85}$.

Esses desenvolvimentos são certamente positivos e os esforços empreendidos pelos Estados latino-americanos durante os últimos anos, a fim de levar sua legislação de proteção ao consumidor e instituições relacionadas a padrões mais elevados e modernos, são louváveis. Simplificando, parece que a "lei nos livros" de proteção ao consumidor na América Latina alcançou as partes mais desenvolvidas do mundo e que o campo de atuação entre fabricantes / distribuidores / vendedores e consumidores / usuários foi nivelado.

No entanto, a aplicação prática dessas leis e o desempenho real das instituições relevantes (a "lei em ação") ainda enfrentam dificuldades que atrapalham a sua eficácia. Por outro lado, existem certas características presentes em outras jurisdições não latinoamericanas que se tornam opções atraentes para as partes latino-americanas que, como resultado, são encorajadas a entrar com ações judiciais e buscar tutela nesses países, em vez de nos seus próprios.

\section{CÃO QUE LADRA E NÃO MORDE? A JORNADA DOS LATINO- AMERICANOS NA BUSCA DE "PASTAGENS MAIS VERDES"}

consumer protection in Brazil. An analysis in the context of property development contracts" (2015) 29 Revista de Derecho Privado 185 n. 23.

${ }^{81}$ Trecho original: "contains a general provision allowing arbitration for disputes arising out of standard form contracts"

${ }_{82} 13$. O dispositivo relevante é o artigo $4^{\circ}$, em que "só confere validade a uma cláusula compromissória de um contrato comum se a cláusula estiver em negrito ou em documento separado e o consumidor a tiver assinado separadamente". Trecho original: "only confers validity to an arbitration clause in a standard contract if the clause is in bold letter or in a separate document and the consumer has signed it separately". Alcici Salomão (2015) Revista de Derecho Privado 195.

83 Trecho original: "regards as null and void any clause that compulsorily imposesarbitration in a B2C contract".

${ }^{84} 185$.

${ }^{85} 204$. 
Os Tribunais dos Estados Unidos têm sido tradicionalmente o foro mais desejado por consumidores latino-americanos para buscar obter soluções jurídicas satisfatórias para danos que resultam do uso de produtos defeituosos, ingestão de substâncias tóxicas, ou sendo alvo de práticas comerciais enganosas. A percepção geral é que o número de processos movidos por demandantes estrangeiros nos Tribunais dos Estados Unidos tem aumentado $^{86}$. Também houve ampla cobertura da mídia sobre muitos casos emblemáticos de direito dos consumidores envolvendo vítimas estrangeiras e réus americanos em uma variedade de setores da indústria ${ }^{87}$. Não obstante, é difícil saber exatamente quantos desses casos tramitaram nos Tribunais americanos, quais os resultados decorrentes e se o arquivamento desses casos nos Estados Unidos seguiu uma estratégia de "forumshopping" ${ }^{\prime 88}$ pelos demandantes estrangeiros.

O fato de muitos fabricantes de produtos serem sediados ou terem contatos significativos com os Estados Unidos, muitas vezes, encorajou os reclamantes latinoamericanos a buscarem reparação nos Tribunais americanos. Dois motivos óbvios são a disponibilidade de provas nos Estados Unidos e a localização dos ativos naquele território, que podem garantir a satisfação de qualquer resultado favorável no litígio. Outras razões estratégicas que fizeram os Estados Unidos ser atrativo para litigar foram: a existência de uma associação de advogados empresariais capaz de financiar processos onerosos, tomando casos em uma base de contingência, com as habilidades necessárias para lidar com mecanismos modernos de coleta de evidências e outras ferramentas processuais eficazes, assim como o conhecimento e recursos para perseguir processos complexos ou de grande porte ${ }^{89}$.

\footnotetext{
${ }^{86} \mathrm{~W}$ Wurmnest. "Foreign Private Plaintiffs, Global Conspiracies, and the Extraterritorial Application of U.S. Antitrust Law" (2004-2005) 28 Hastings Int'l \& Comp L Rev 205, 215.

${ }^{87}$ HL Kaplan, WJ Crampton \& ME Shelley. Class Action Developments Overseas-Chapter 7, in Product Liability Litigation: Current Law, Strategies and Best Practices. The Practising Law Institute (2012) 7-35 et seq.

${ }^{88}$ N.T.: Refere-se à prática de escolher o Tribunal ou jurisdição que tem as leis ou posição jurisprudencial mais favorável ao demandante, escolhendo aquela que concede uma vantagem em relação ao demandado. 89 Para uma história abrangente de litígios empresariais nos Estados Unidos, ver JC Coffee Jr. Entrepreneurial Litigation: Its Rise, Fall, and Future (2015). Para a expansão do contencioso empresarial para outros países, ver, JC Coffee Jr "The Globalization of Entrepreneurial Litigation: Law, Culture, and Incentives" (2017) 165 University of Pennsylvania Law Review 1895.
} 
Alguns compararam a atratividade dos Tribunais dos Estados Unidos, para litigantes estrangeiros, à influência que uma fonte de luz tem sobre uma mariposa ${ }^{90}$. Essa metáfora, originalmente empregada por um juiz inglês há mais de trinta e cinco anos, pode parecer um exagero pitoresco. Sugere-se que litigantes estrangeiros se comportam impulsivamente, e que também a sua jurisdição interna é lamentavelmente inadequada para oferecer-lhes uma reparação apropriada; enquanto, por outro lado, os tribunais americanos são os paradigmas de eficiência. Um olhar mais atento ao estado atual das coisas revela que nenhuma dessas caracterizações extremas é completamente precisa. Conforme explicamos anteriormente, os países latino-americanos têm (nos últimos anos) feito grandes avanços no sentido de modernizar sua infraestrutura jurídica para fornecer um sistema adequado de proteção ao consumidor, incluindo mecanismos judiciais.

Por outro lado, o sistema de responsabilidade civil americano tem sido criticado por impor custos injustificados aos réus por meio de "julgamentos exagerados, por confiar em veredictos imprevisíveis do júri e por desencorajar a inovação tecnológica, com base em que as empresas consideram temerário arriscar a introdução de novos produtos por medo de uma potencial falência induzida por lei de responsabilidade civil ${ }^{\prime \prime 1}$

O sistema de contencioso civil dos Estados Unidos está longe de ser perfeito, mas ainda pode oferecer uma chance melhor aos demandantes latino-americanos, se comparado aos Tribunais de suas jurisdições de origem ${ }^{92}$. Com maiores chances de se recuperar de um réu "deep pocket" situado nos Estados Unidos, seja por meio de um acordo ou como resultado de uma decisão judicial, por ser capaz de contar com uma associação de demandantes sofisticada, para aproveitar a disponibilidade de ferramentas de prova modernas e eficazes como a descoberta eletrônica e um sistema judicial que funciona razoavelmente, as recompensas para um demandante latino-americano por litigar nos Estados Unidos são palpáveis.

\footnotetext{
${ }^{90}$ Ver Smith Kline \& French Laboratories, Ltd. v Bloch [1983] 2 All E.R. 72, 74, 1 W.L.R. 730 (C.A. 1982) (Lord Denning MR): "As a moth is drawn to the light, so is a litigant drawn to the United States. If he can only get his case into their courts, he stands to win a fortune."

${ }^{91}$ SD Sugarman "United States tort reform wars" (2002) 25 The University of South Wales Law Journal (2002) 1.

${ }^{92}$ Gómez (2005) Southwest Journal of Law and Trade in the Americas 11.
} 
Existem, no entanto, certos obstáculos que se interpõem, como a resistência - nada surpreendente - dos réus americanos, para os quais as vantagens percebidas do sistema de litígio civil dos Estados Unidos podem ser taticamente indesejáveis. Como resultado, é prática comum para os réus americanos buscarem a extinção dos casos movidos contra eles por demandantes estrangeiros e propor, em vez disso, que o litígio aconteça em Tribunais estrangeiros. Tal estratégia defensiva leva o tribunal americano a se engajar em uma análise em duas etapas em que pondera os diferentes fatores (de interesse público e privado) que tornam um foro (por exemplo, aquele escolhido pelo reclamante) mais adequado do que o outro (por exemplo, foro estrangeiro "alternativo") para fins do litígio.

Se o Tribunal americano decidir aceitar os argumentos apresentados pelo réu, o caso é encerrado em favor do foro estrangeiro alternativo e mais conveniente, levando assim o autor a apresentar novamente sua reclamação em outro lugar para que o litígio continue. Há casos em que a extinção por um Tribunal dos Estados Unidos terá efeitos dispositivos sobre o caso porque o reclamante estrangeiro acaba não ajuizando novamente sua reclamação no Tribunal estrangeiro.

Isso pode ocorrer por uma variedade de razões, mas uma das mais comumente citadas é que, a despeito da decisão do Tribunal americano (que considerou o foro estrangeiro adequado), a realidade mostra o contrário. Por outro lado, houve excepcionais - situações em que não apenas os demandantes estrangeiros puderam apresentar novamente o seu caso em sua jurisdição de origem após uma extinção, mas também obtiveram resultados significativamente mais favoráveis do que aqueles que teriam obtido de um Tribunal americano ${ }^{93}$.

\footnotetext{
${ }^{93}$ O exemplo paradigmático de uma vitória legal de "segunda chance" após a rejeição do litígio nos tribunais dos Estados Unidos é o caso de Aguinda v. Texaco/Chevron (também conhecido como saga ChevronEquador), em que um tribunal equatoriano proferiu uma sentença multibilionária em favor dos demandantes, quando o caso foi arquivado por um Tribunal Federal dos Estados Unidos, com base no Forum Non Conveniens. Este caso, entretanto, gerou controvérsia significativa com base, entre outras coisas, nas alegações da réu norte-americano Chevron Corporation, de que a sentença equatoriana foi obtida por meio de fraude. Como resultado, a empresa multinacional agiu com sucesso para bloquear a execução de tal sentença nos Estados Unidos após obter outra decisão de um Tribunal dos Estados Unidos que determina que o litígio estrangeiro foi de fato produto de fraude. Mais recentemente, um tribunal arbitral internacional nomeado para decidir uma reclamação estatal de investidor relacionada registrada pela Chevron e Texaco contra a República do Equador concluiu que as ações equatorianas também violaram o direito internacional e negaram justiça às empresas americanas. Para uma visão geral deste caso, consulte M Gómez "A sour battle in Lago Agrio and beyond: The metamorphosis of transnational litigation and the protection of collective rights in Ecuador" (2015) 46 University of Miami Inter-American Law Review
} 
Esta doutrina judicial, apelidada de "Forum Non Conveniens", "que os recursos privados e públicos sejam geridos de forma eficiente no contexto de litígios envolvendo partes estrangeiras em um dos dois lados do caso" "95. Não obstante, sua aplicação tem sido frequentemente criticada por falta de coerência e previsibilidade ${ }^{96}$. A possibilidade de um Tribunal americano rejeitar uma ação ajuizada por um demandante estrangeiro (isto é, latino-americano) nos Estados Unidos foi veementemente rejeitada por algumas legislaturas latino-americanos, por considerá-la contrária à noção de acesso à justiça.

Como resultado, pelo menos três jurisdições latino-americanas promulgaram "estatutos de bloqueio" que impedem que a doutrina do Forum Non Conveniens seja aplicada a seus cidadãos que optam por mover sua ação nos Estados Unidos. Essas leis funcionam excluindo a possibilidade de ajuizar uma ação em seu território depois que ela foi indeferida em outro lugar, ou impondo sanções ou consequências adversas às partes que optaram por litigar em outro lugar primeiro $^{97}$.

De volta à América Latina, os consumidores têm aproveitado cada vez mais as vantagens dos modernos veículos processuais que permitem o ajuizamento de reivindicações agregadas de maneira semelhante às ações coletivas dos Estados Unidos; mas ainda existem alguns desafios. Em primeiro lugar, algumas jurisdições apenas conferem legitimidade a certas entidades governamentais ou associações de consumidores especialmente estabelecidas e registradas. Em segundo lugar, a tendência entre os estatutos semelhantes à ação de classe promulgados na região também tem sido a eliminação de quaisquer incentivos financeiros potenciais para o representante de classe ou advogado de classe ${ }^{98}$. Em terceiro lugar, os acordos de taxas de contingência e o

153. Consulte também, M Gómez "The Global Chase: Seeking the Recognition and Enforcement of the Lago Agrio Judgment Outside of Ecuador" (2013) 1 Stan J Complex Lit 101.

${ }^{94}$ C.f. Piper Aircraft Co. v Reyno 454 U.S. 235 (1981).

${ }^{95} \mathrm{JH}$ Samuels "When is an Alternative Forum Available? Rethinking the Forum Non Conveniens Analysis" (2010) 85 Indiana Law Journal 1059, 1060.

${ }^{96}$ CB Robertson "Forum Non Conveniens on Appeal: The Case for Interlocutory Review" (2012) 18 Southwestern Journal of International Law 445, 446.

${ }^{97}$ Cf., eg Article 1421-J, Special Procedure for Resolving International Disputes (Panama); Decree 34-97, Law of Defense of Procedural Rights of Native Citizens and Residents (Guatemala); and Special Law 364 of 17 January 2001 (Nicaragua). Para uma discussão sobre a aplicação da lei de bloqueio da Nicarágua, consultar J Todd "Phantom Torts and Forum Non Conveniens Blocking Statutes: Irony and Metonym in Nicaraguan Special Law" (2012) 43 University of Miami Inter-American Law Review 291-324.

${ }^{98}$ Para um comentário detalhado dos principais regimes de litígio de grupo na América Latina, consultar Gómez (2012) 43 Univ Miami Inter- American L Rev 3; Cf., HL Kaplan, WJ Crampton \& ME Shelley 
financiamento de litígios externos são limitados ou inexistentes; e em quarto lugar, a possibilidade de obter "danos punitivos" e outras formas de danos exemplares geralmente não está disponível.

Como resultado, os consumidores não tiveram outra opção a não ser continuar a contar com outros mecanismos processuais, como o mandado de "amparo constitucional" (também conhecido como "tutela" na Colômbia ou "mandado de segurança" no Brasil), que é um procedimento extraordinário contra determinado ato, conduta ou omissão atribuída a um indivíduo, órgão governamental ou entidade privada, que represente ameaça iminente aos direitos constitucionais de outra pessoa ${ }^{99}$. Isso, obviamente, inclui a proteção dos direitos relacionados aos consumidores e usuários, que, como explicado anteriormente, também são geralmente protegidos pelas Constituições de diferentes países latino-americanos.

Apesar de sua hierarquia constitucional, muitas jurisdições latino-americanas permitem que peticionários individuais intentem ações de amparo em Tribunais inferiores com base em violações constitucionais cometidas pelo governo, o que inclui qualquer entidade pública, e também por partes privadas, incluindo empresas e prestadores de serviços. Em seguida, os Tribunais Constitucionais (ou "Câmaras" no caso da Venezuela e da Costa Rica) decidem se exercem ou não o controle a posteriori sobre as decisões dos tribunais inferiores, concedendo um certiorari para julgar e fazer cumprir os direitos em favor dos cidadãos. Esta é a forma mais comum de os Tribunais latino-americanos exercerem a adjudicação e o cumprimento de direitos concretos e difusos.

Em linhas gerais, as ações de amparo são mecanismos eficientes e ágeis de proteção dos direitos fundamentais, inclusive os relacionados às relações de consumo. Os Tribunais investidos com o poder de decidir esses casos constitucionais recebem rotineiramente autoridade abrangente, seus processos também são tratados como questões

Class Action Developments Overseas-Chapter 7, in Product Liability Litigation: Current Law, Strategies and Best Practices. The Practising Law Institute (2012) 7-35 et seq; A Gonçalves de Castro Mendes \& LC Pochmann da Silva Incident of Resolution of Repetitive Demands (IRDR) and Repetitive Appeals in the New Brazilian Civil Procedure Code (2016) <https://classactionblawg.files.wordpress.com/2016/04/ repetitive-pleas-in-the-brazilian-new-civil-procedure-code.pdf $>$ (accessed 16-02-2019). Cf., A Barroilhet "Class Actions in Chile" (2012) 18 Law and Business Review of the Americas 275.

99 Cf., eg Organic Law of Amparo and Constitutional Guarantees (Ley Orgánica de Amparo sobre Derechos y Garantías Constitucionales, or Amparo Statute), Official Gazette 34,060 of September 27, 1988 (Venez.), arts 2, 3, 4. 
urgentes e as sanções impostas pelo não cumprimento de suas ordens constitucionais são geralmente mais severas do que os recursos comuns ordinariamente veiculados perante Cortes civis e comerciais.

Em alguns países, como a Venezuela, a recusa em cumprir uma ordem de amparo pode resultar na prisão da parte recalcitrante ${ }^{100}$. Apesar dessa dureza, que pode ser interpretada por alguns como vantajosa, os pedidos de amparo são formas incompletas de proteção dos direitos do consumidor na América Latina. A razão principal é que a tutela concedida em ação de amparo sempre tem caráter liminar. Muitas vezes, a razão pela qual os consumidores buscam uma reparação judicial é justamente para obter uma reparação ou indenização monetária. Em outros casos, a constitucionalidade da reclamação não é tão evidente, de modo que a eficácia de uma ação de amparo pode ser nada mais do que uma ilusão.

\section{CONCLUSÃO: "AINDA SEM MORDER"}

Conforme descrito no artigo, nos últimos anos testemunhou-se um significativo progresso no que tange ao avanço das políticas de proteção ao consumidor na região da América latina. A despeito das muitas diferenças entre os sistemas jurídicos nacionais, tem havido algumas tentativas de harmonizar o sistema jurídico em toda a região.

Do projeto da CIDIP-VII, elaborado sob a égide da OEA, ao significativo esforço realizado pela UNCTAD, com o apoio do Governo suíço, vários países agora podem coordenar suas atividades e trabalhar para harmonizar seus regimes jurídicos. Particularmente, a iniciativa da UNCTAD - atualmente denominada COMPAL - iniciada como um esforço modesto, envolvendo apenas sete países, agora se expandiu para incluir $75 \%$ (setenta e cinco por cento) da região, incluindo algumas das maiores economias do hemisfério, como Argentina, Brasil e México. O COMPAL também é autossustentável e seus resultados positivos são palpáveis.

Não obstante essa perspectiva otimista, ainda existem alguns obstáculos importantes que se interpõem e que impediram esses sistemas modernizados de proteção ao consumidor de atingir alguns de seus objetivos. Nesse ínterim, os consumidores latino-

${ }^{100}$ Artigo 31. 
americanos continuaram migrando para Tribunais estrangeiros (mais tipicamente para os Estados Unidos), onde as condições frequentemente eram vistas como favoráveis a demandantes estrangeiros.

As grandes empresas, que geralmente são alvos dessas ações estrangeiras, também lutaram e desenvolveram estratégias destinadas a repelir o que consideram um ataque em seu fórum de origem. Os Tribunais americanos responderam de maneira heterogênea, assim como os sistemas jurídicos latino-americanos, aos quais pertencem os demandantes. Em suma, o cenário é complicado e aqueles que sofrem as consequências mais adversas são os consumidores que - como uma bola em jogo - são jogados para frente e para trás entre os sistemas jurídicos, e, muitas vezes, privados de qualquer reparação significativa como resultado.

Uma forma possível de mitigar esse problema seria alcançada se os países latinoamericanos prestassem mais atenção à garantia de acesso dos consumidores a meios locais e eficazes de proteção judicial; em outras palavras, que os remédios existentes não "só ladrassem, mas também mordessem".

\section{REFERÊNCIAS:}

A Werner Latin America and the Caribbean in 2019: A Moderate Expansion. IMFBlog, 2019. Disponível em: https://blogs.imf.org/2019/01/25/latin-america-and-thecaribbean-in-2019-a- moderate-expansion/.

Alianza Bolivariana para los pueblos de nuestra América. Disponível em: tp://www. portalalba.org/.

ASSEMBLEIA GERAL DAS NAÇÕES UNIDAS. Diretrizes sobre Proteção ao Consumidor, Documento UN Doc A / RES / 39/248, 16 de abril de 1985. Disponível em: http://www.un.org/documents/ga/res/39/a39r248.htm.

BANCO MUNDIAL. Global Economic Prospects: Latin America and the Caribbean Brief. Worldbank, 2018. Disponível em: https://www.worldbank.org/en/region/lac/brief/global-economic-prospects-latinamerica- and-the-caribbeana. 
BARROILHET, A. Class Actions in Chile. 18 Law and Business Review of the Americas 275. 2018.

BARROILHET, Agustín. The Regime Politics Origins of Class Action Regulation. 19 Theoretical Inquiries L 363, 2018.

BRASIL. Código de defesa do consumidor, de 11 de setembro de 1990. Disponível em: http://www.planalto.gov.br/ccivil_03/leis/L8078.htm.

BRASIL. Lei de ação civil pública, de 24 de julho de 1985. Disponível em: http://www.planalto.gov.br/ ccivil_03/Leis/L7347orig.htm.

BRUSICK, P.;ALVAREZ, AM.; HORNA, PM. Fortalecendo instituições e capacidades na área de Política de Concorrência e Defesa do Consumidor, documento das Nações Unidas UNCTAD/DITC/CLP/2004/3.

CANADÁ. Lista de comentários do Canadá à proposta conjunta da Argentina, Brasil e Paraguai para um projeto de Convenção Interamericana sobre a Lei Aplicável a Alguns Contratos e Transações Internacionais de Consumo, documento da OEA/Ser/G CP/CAJP-2823/10 de 14 de abril de 2010.

CANADÁ. Lista de comentários do Canadá à proposta conjunta da Argentina, Brasil e Paraguai para um projeto de Convenção Interamericana sobre a Lei Aplicável a Alguns Contratos e Transações Internacionais de Consumo, documento da OEA/Ser/G CP/CAJP-2823/10 de 14 de abril de 2010.

CÁRDENAS, M. LATAM Consumer \& Retail: The Good, the Bad and Ugly for 2018. Perspectiva, Market Insights for Success in Latin America, 2018. Disponível em: https://amiperspectiva.americasmi.com/latam-consumer-retail-the-good-badand-ugly-for-2018/.

CASTRO MENDES, A. Gonçalves de; DA SILVA, LC. Pochmann. Incident of Resolution of Repetitive Demands (IRDR) and Repetitive Appeals in the New Brazilian Civil Procedure Code. Wordpress, 2016. Disponível em: https://classactionblawg.files.wordpress.com/2016/04/ repetitive-pleas-in-thebrazilian-new-civil-procedure-code.pdf.

CASTRO, C.; REED, C.; DE QUEIROZ, R. On the applicability of the Consumer Protection Code to cloud computing transactions in Brazil. 10 Script-Ed 459, 471, 2013. 
CHILE. Lei de Protección al Consumidor, de 2 de julho de 2004.

COFFEE, J.C. JR. Entrepreneurial Litigation: Its Rise, Fall, and Future (2015)

COFFEE, J.C. JR. The Globalization of Entrepreneurial Litigation: Law, Culture, and Incentives. 165 University of Pennsylvania Law Review 1895, 2017.

COLE, T.; ORTOLONI, P; KARACAN, P.; CARDOSO, S. Trindade. Arbitration in the Americas: Report on a Survey of Arbitration Practitioners. University of Leicester \& Gentium Law, 2018.

COLÔMBIA. Popular and Group Actions Act, de 5 de agosto de 1998.

COMPAL. III Relatório Anual (2017-2018). Disponível em: https://unctadcompal.org/wp-content/uploads/2018/07/ COMPAL-III_InformeAnnual-2017-2018.pdf.

COMPAL. About Compal. UNCTADCOMPAL, s.d. Disponível em: https://unctadcompal.org/acerca-del- compal/.

CONSELHO ECÔNOMICO E SOCIAL. Conferência das Nações Unidas sobre Comércio e Desenvolvimento, Diretrizes das Nações Unidas sobre Defesa do Consumidor. Revisadas e aprovadas na resolução 70/186, de 22 de dezembro de 2015, pela Assembleia Geral, Documento UNCTAD/DITC/CPLP/MISC/2016/1. Disponível em: http://unctad.org/en/PublicationsLibrary/ ditccplpmisc2016d1_en.pdf.

DENNIS, S. Omnichannel is Dead. Long Live Omnichannel. Forbes, 2017. Disponível em: https://www.forbes. com/sites/stevendennis/2017/03/23/omni-channel-isdead-long-live-omni-channel/\#206ec7835215.

ESQUIROL, JL. Continuing Fictions of Latin American Law. 2003, 55 Fla L Rev 41.

ESTADOS UNIDOS DA AMÉRICA. Proposta dos Estados Unidos da América para a Sétima Conferência Interamericana Especializada em Direito Internacional Privado (CIDIP-VII), documento CP/CAJP-2837/10 de 21 de abril de 2010.

GÓMES, M. A sour battle in Lago Agrio and beyond: The metamorphosis of transnational litigation and the protection of collective rights in Ecuador. 46 University of Miami Inter-American Law Review 153, 2015. 
GÓMES, M. Like Migratory Birds - Latin American Claimants in U.S. Courts and the Ford- Firestone Rollover Litigation. 21 Southwest Journal of Law and Trade in the Americas 11, 2005.

GÓMES, M. The Global Chase: Seeking the Recognition and Enforcement of the Lago Agrio Judgment Outside of Ecuador. 1 Stan J Complex Lit 101, 2013.

GÓMES, M. The South American Way: Sub-regional integration under ALBA and UNASUL and international dispute resolution. 58 Húngaro Journal of Legal Studies-Acta Juridica Hungarica 449, 2017.

GÓMES, M. Will the Birds Stay South? The Rise of Class Actions and Other Forms of Group Litigation Across Latin America. 43 Univ Miami Inter-American L Rev 3, 2012.

GUATEMALA. Law of Defense of Procedural Rights of Native Citizens and Residents, Decree 34-97.

Introdução Explicativa ao Encontro de Especialistas realizado pela OEA, Porto Alegre, Brasil, dezembro de 2006. Disponível em: https://www.oas.org/dil/experts_meeting_porto_alegre_2-4_2006.pdf.

INVESTOPEDIA. eCommerce. Disponível em: https://www.investopedia.com/ terms/e/ecommerce.asp.

KAPLAN, HL.; CRAMPTON, W.J.; SHELlEY, M.E. Class Action Developments Overseas-Chapter 7, in Product Liability Litigation: Current Law, Strategies and Best Practices. The Practising Law Institute, 2012.

LOZADA, J. Espinoza; LOPEZ, CM.; BÉJAR, V. Vergaray. Arbitraje de Consumo, Escuela Nacional Indecop. Indecopi, 2016. Disponível em: https://www.indecopi.gob.pe/documents/51084/126949/ArbitrajeDeConsumo_2 016/a70602fb-ac42-b932-5ced-0430545ee966.

MEXICO. Constitución Política de los Estados Unidos Mexicanos.

MÉXICO. Decreto pelo qual se reforma e adiciona ao: Código Federal de Procedimientos Civiles, Código Civil Federal, Ley Federal de Competencia Económica, Ley Federal de Protección al Consumidor, Ley Orgánica del Poder Judicial de la Federación, Ley General del Equilibrio Ecológico y la Protección del Ambiente, Ley de Protección y Defensa al Usuario de Servicios Financieros, 
de 30 de agosto de 2011. Disponível em: http://dof.gob.mx/nota_detalle.php?codigo=5206904\&fecha=30/08/2011.

MILLER, B; STEIKER-GINZBERG, K. Projected GDP in Latin America for 2018. Americas Quarterly. Disponível em: https://www.americasquarterly.org/content/projected-gdp-growth-latin-america2018.

NICARAGUA. Special Law, $n^{\circ}$ 364, de 17 de Janeiro 2001.

OECD. Protección del consumidor y comercio electrónico, Capítulo 13, in Políticas de banda ancha para América Latina y el Caribe: Un manual para la economía digital. 2016. Disponível em: https://www.oecd-ilibrary.org/science-andtechnology/politicas-de-banda-ancha-para-america-latina-y-el-caribe/protecciondel-consumidor-y-comercio- electronico_9789264259027-16-es.

Organização dos Estados Americanos. Disponível em: http://www.oas.org/dil/cidipvii_home.htm.

ORGANIZAÇÕES DOS ESADOS AMERICANOS. CIDIP VII Consumer Protection nos Estados Unidos. OEA. Disponível em: http://www.oas.org/dil/CIDIPVII_consumer_protection_united_states.htm.

PANAMA. Special Procedure for Resolving International Disputes.

PÉREZ, AF. Defesa do Consumidor nas Américas: Uma Segunda Onda de Revoluções Americanas? 5 U St. Thomas LJ, 2018.

PROCONSUMER. Sistema de Consumo Nacional de Arbitraje. Disponível em: http://www.proconsumer.org.ar/index.php/80-proconsumer/123-snac.

Resolução da Assembleia Geral da Assembleia Geral da Organização dos Estados Americanos, documento AG/RES. 2065 (XXXV-O/05), Sessão Plenária de 7 de Junho de 2005.

ROBERTSON, C.B. Forum Non Conveniens on Appeal: The Case for Interlocutory Review. 18 Southwestern Journal of International Law 445, 446. 2012.

SALOMÃO, D. Alcici. Effective methods of consumer protection in Brazil. An analysis in the context of property development contracts. 29 Revista de Derecho Privado 185 n 23, 2015. 
SAMUELS, J.H. When is an Alternative Forum Available? Rethinking the Forum Non Conveniens Analysis. 85 Indiana Law Journal 1059, 1060. 2010.

SÁNCHES, AMR.; SALAZAR, LFG. Esduerzos Latino americanos en torno a los derechos del consumidor: CAN y Mercosur. 89.1 Revista Relaciones Internacionales 171, 2016.

SMITH, KLINE \& FRENCH LABORATORIES, Ltd. v Bloch [1983] 2 All E.R. 72, 74, 1 W.L.R. 730 (C.A. 1982).

SUGARMAN, S.D. United States tort reform wars. 25 The University of South Wales Law, 2002.

TODD, J. Phantom Torts and Forum Non Conveniens Blocking Statutes: Irony and Metonym in Nicaraguan Special Law. 43 University of Miami Inter-American Law Review 291-324. 2012.

UNIÃO DAS NAÇÕES SUL-AMERICANAS. Disponível em: https:// www.unasursg.org/en. Acesso: 16-02-2019.

VENEZUELA. Ley Orgánica de Amparo sobre Derechos y Garantías Constitucionales, or Amparo Statute, de 27 de setembro de 1988.

WURMNEST, W. Foreign Private Plaintiffs, Global Conspiracies, and the Extraterritorial Application of U.S. Antitrust Law. 28 Hastings Int'1 \& Comp L Rev 205, 215, 2005. 